\title{
Concrete production - an application of OC curves in conformity control
}

\author{
Izabela Skrzypczak ${ }^{1, *}$ \\ ${ }^{1}$ Rzeszow University of Technology, Powstancow Warszawy 12, 35-082 Rzeszow, Poland
}

\begin{abstract}
The decision on conformity or non-compliance of strength is made on the basis of a comparison of the results of testing of the mean value and minimum value of the compressive strength of concrete with the compliance criterion. This decision is made on the basis of the adopted statistical quality control plan. The quality monitoring of concrete has to be carried out throughout its production process. There are various techniques for the monitoring of quality concrete, namely Control charts: Cusum, Schewart and EWMA Control charts or operational-characteristic (OC) curve and average outgoing quality curve. In the case of concrete quality control, it may be an OC curve of a random sampling plan according to a numerical value or alternative evaluation, or an OC curve of the operational rule for testing concrete strength. The paper presents an analysis and assessment of the risk associated with making the second type of error related to compressive strength of concrete. For analysis, the OC curve of the operational rule for testing concrete strength, with OC curve of the second type of error was used as a function of the actual average compressive strength of the concrete.
\end{abstract}

\section{Operating-characteristic curves in conformity control}

The operating characteristic (OC) curves measure the performance of a sampling plan. This can be used to find out the risk to the producer as well as the consumer. In the context of concrete plants, the producer's risk is associated with the risk of a good quality concrete being rejected by the client, while the consumer's risk is associated with the risk of accepting a poor quality concrete. Quality monitoring deals with the monitoring techniques applied during the production of the ready mixed concrete in concrete plants. The 28 day compressive strength cube data of concrete grades have been collected from concrete plants in Podkarpacie Province and attempts have been made to investigate the producer's risk as well as consumer's risk, which would enable concrete producers and consumers to assure quality levels.

Quality monitoring of concrete has to be carried out throughout its production process. There are various techniques for the monitoring of concrete, namely control charts such as Cusum Control charts, Schewart Control charts, and the EWMA Control charts Acceptance Sampling $[1,2]$ of the concrete control system. However, if the concrete producers adopt any of the above monitoring techniques, it would enable them to produce and sell a quality

*Corresponding author: izas@prz.edu.pl 
product at reasonable prices. The operating characteristic curves which measure the performance of a sampling plan can be utilized for finding out the producer's risk (associated with the risk of a good quality concrete being rejected by the client) and the consumer's risk (associated with the risk of accepting a poor quality concrete). In this paper, an attempt has been made to plot the OC curves for C 20/25 concrete class collected from concrete plants in Podkarpacie Province. The collected 28 day cube strength data for the $\mathrm{C} 20 / 25$ concrete class produced by concrete plants have been utilized in finding out the producer's risk, the average quality level, the consumer's risk and the limiting quality level from the plotted OC curves. These parameters would provide adequate information on assuring the quality levels for concrete producers as well as consumers.

In the assessment of different sampling plans, it helps to compare how they fulfill their task at different possible levels of quality of the controlled product. The statistical quality control theory shows that there are two types of operational-characteristic curves. In this case we are interested in the acceptance control of a particular batch as a function of its fraction of incompatible (defective) units, or if we are interested in verification of the obtained values using statistical tests. Graphs of the probability dependence of $\mathrm{Pa}$ on defects in (number of missing items in the lot) or diagrams of the dependence of probability of rejection from the operating rule of testing (eg, average strength) are the operational and characteristic curves (OC curves). Random sampling plans are a traditionally used, suggestive form of risk presentation related to statistical compliance criteria. The operational-characteristic curves called acceptance test plans are a special case of statistical tests known in statistics. Using statistical terminology, we can state that party acceptance corresponds to the case when there is no basis for rejecting the null hypothesis defectivness $<\mathrm{AQL}$, where the value of AQL is called the quality corresponding to the risk of the supplier $\alpha$. In turn, the rejection of the batch corresponds to the rejection of the null hypothesis - defectivness $<\mathrm{AQL}$ in favor of the alternative hypothesis - defectivness $>$ LQL, where LQL - the quality corresponding to the risk of the consumer. The probability of making the second type of error is called the risk of the $\beta$ producer.

The operating characteristic (OC) curve measures the performance of an accepting sampling plan. This curve plots the probability of accepting the lot versus proportion nonconforming. Thus, the OC curve displays the discriminatory power of the sampling plan and it shows the probability that a lot submitted with a certain fraction defective will be either accepted or rejected. If the producer designs for $97.5 \%$ of concrete to be above the specified strength when the theoretical basis of the compliance rules is $95 \%$, the risk of failure for any normal size contract is acceptably low. By this approach, the ready-mix concrete industry runs less risk problems with each individual small contract and also safeguards larger contracts and its overall production Thus, the conventional way by which probabilities may be judged by both the producer and the consumer is through the use of the operating characteristic curve (Fig. 1). For any compliance clause, the producer may assess the risk of having complying concrete rejected (producer's risk) and the consumer can assess the risk of accepting non-complying concrete (consumer's risk). In a hypothetical control, the producer's risk and consumer's risk are both nil. In practice, diagrams are usually of the form of Figure 1, where both sides (consumer and producer) run some risk.

The key elements of an OC curve are described as follows (Fig. 1). 


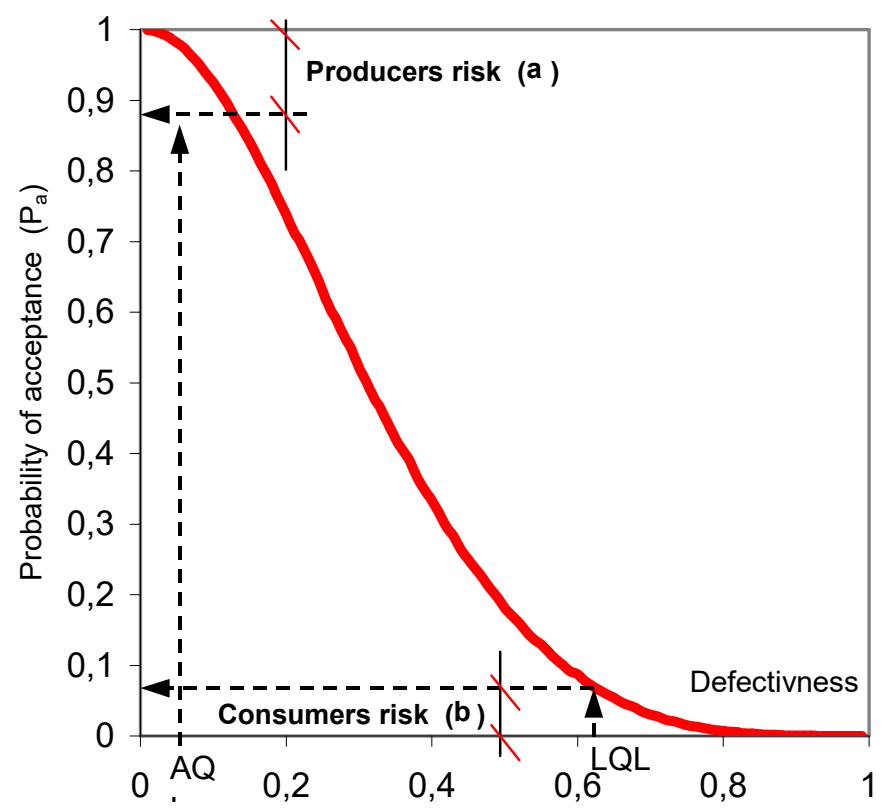

Fig 1. OC curve showing (AQL, $1-\alpha)$ and (LQL, $\beta$ ).

Producer's risk - $\alpha$. This is the risk associated with rejecting a lot of good quality. It is generally denoted by $\alpha$. Since $\alpha$ is expressed in terms of the probability of non-acceptance, it cannot be located on an OC curve unless it is specified in terms of probability of acceptance. This conversion is given below: Probability of acceptance $\left(\mathrm{P}_{\mathrm{a}}\right)=1-\alpha$.

Acceptable quality level - AQL. This is the numerical definition of a good lot, associated with the producer's risk a. Thus, the AQL is a percent defective that is the base line requirement for the quality of the producer's product. The producer would prefer the sampling plan to have a high probability of accepting a lot that has a defect level less than or equal to the AQL.

Consumer's risk $-\beta$. This is the risk associated with accepting a lot of poor quality. It is generally denoted by $\beta$. Limiting the quality level of LQL. This is a numerical definition of a poor lot associated with the consumer's risk. Thus, the LQL is a designated high defect level that would be unacceptable to the consumer. The consumer would prefer the sampling plan to have a low probability of accepting a lot with a defect level as high as the LQL.

To construct an OC curve, we assume that the process produces a stream of lots and the lot size is large and the probability of the non-conforming item is small.

The OC curve has the following properties:

- OC curve in general is continuous in nature;

- When defectiveness is 0 then $\mathrm{P}_{\mathrm{a}}=1$ i.e. lots with defectives must always be accepted;

- When defectiveness is 1 then $\mathrm{P}_{\mathrm{a}}=0$ i.e. lots with defectives must always be rejected. All defectives must always be rejected.

The probability of the acceptance of lots with few defectives can be identified from the OC curve plotted for that particular case.

All OC curves passes through points (0.1) and (1.0). As $\mathrm{P}$ increases $\mathrm{P}_{\mathrm{a}}$ decreases and vice-versa. The points on the OC curve are (LQL, 1- $\alpha$ ), (AQL, $\beta$ ) where a denotes the producer's risk, and b denotes the consumer's risk. The above parameters can also be represented by the decision in Table 1. 
Table 1. Producers risk and consumers risk of a lot.

\begin{tabular}{|c|c|c|c|}
\hline \multicolumn{2}{|c|}{} & \multicolumn{2}{c|}{ Result of Decision } \\
\cline { 3 - 4 } & Accept the lot & Reject the lot \\
\hline \multirow{3}{*}{ Quality of lot } & Good lot (AQL) & - & $\begin{array}{c}\text { Producer risk - } \beta \\
\text { (Type - I I Error) }\end{array}$ \\
\cline { 2 - 4 } & Bad lot (LQL) & $\begin{array}{c}\text { Consumer risk - 1- } \alpha \\
\text { (Type - I Error) }\end{array}$ & - \\
\hline
\end{tabular}

So, the rational compliance criteria should meet at least three basic conditions:

- The probability of $\mathrm{Pa}$ acceptance of a batch of concrete meeting the requirements 1- $\alpha$, i.e. the risk of a concrete producer, (the risk of rejection of a batch that meets the requirements) should not be less than the pre-determined one and should take into account the tradeoff between the risk of $\beta$ producer and 1- $\alpha$ consumer (batch acceptance risk not meeting the requirements),

- An increase in sample size $n$ should increase the value of $P_{a}$, i.e. reduce the risk of the producer $\beta$,

- Among batches that meet the requirements, higher $\mathrm{P}_{\mathrm{a}}$ values should correspond to batches with a smaller standard deviation in concrete production.

The decision to pass the considered batch of concrete to the designed class depends primarily on the fulfillment of the condition imposed on the mean value strength of the sample, very rarely the decisive condition is the limitation of the mean value strength in the sample. In the case of individual criteria related to the mean value or minimum value of the sample, the calculation of the ordinates of the OC curve is quite easy. The application of a single type compliance criterion was analyzed, among others in $[3,4]$. The compliance criteria proposed in the standard are an expression of a compromise between the requirements of safety, economy and quality [5-20]. Due to the quality of the designed concrete constructions, the criterion imposed on the mean value strength can be considered using the operating-characteristic curve of the operational rule for testing the actual average compressive strength.

\section{Conformity criteria of the compressive strength of concrete}

The compressive strength of concrete is treated as a random variable and described by the means of two parameters; the average value and the standard deviation. In the design standards for concrete and reinforced concrete structures, the concrete's mechanical properties depend on the characteristic strength. This size was defined as a 5\% quantile of the compressive strength distribution of concrete. When verifying compliance of the strength of the considered batch of concrete with the designed characteristic strength (class of concrete) it should be checked whether the results of sample tests meet the relevant statistical criteria for mean value and minimum vaule of compressive strength. The quantitative criteria for assessing the conformity of the compressive strength of concrete can be verified by statistical methods including: classic statistical inference, OC curves, and Bayesian inference. The application of statistical conformity criteria requires knowledge of the actual defectiveness of the tested batch of concrete, which can only be estimated in an approximate way, even in the case of continuous concrete production. The decision on the conformity or non-conformity of the compressive strength is made on the basis of a comparison of the results of testing the samples with the criterion of conformity taking into account both the risk of the producer and the consumer. The Conformity criteria for compressive strength are formulated in EN 206 [13]. Conformity criteria shall be made as a result of test results taken during an assessment 
period that shall not exceed the last twelve months. Conformity is confirmed if both the criteria given in Table 2 for either initial or continuous production are satisfied.

Table 2. Conformity criteria for compressive strength [13].

\begin{tabular}{|c|c|c|c|}
\hline \multicolumn{2}{|c|}{} & Criterion 1 & Criterion 2 \\
\hline Production & Sample size & $\begin{array}{c}\text { Mean of } \mathrm{n} \text { results }\left(\mathrm{f}_{\mathrm{cm}}\right) \\
{\left[\mathrm{N} / \mathrm{mm}^{2}\right]}\end{array}$ & $\begin{array}{c}\text { Any individual test } \\
\text { result }\left(\mathrm{f}_{\mathrm{ci}}\right)\left[\mathrm{N} / \mathrm{mm}^{2}\right]\end{array}$ \\
\hline Initial & Not less than 15 & $\geq \mathrm{f}_{\mathrm{ck}}+4$ & $\geq \mathrm{f}_{\text {ck }}-4$ \\
\hline Continuous & Less than 15 & $\geq \mathrm{f}_{\text {ck }}+1.48 \sigma$ & $\geq \mathrm{f}_{\text {ck }}-4$ \\
\hline
\end{tabular}

\section{Case study - OC curves as a function of the real mean value}

The presented example was developed on the basis of the results of concrete compressive strength tests obtained from concrete production plants operating in the Podkarpacie region [28]. An analysis and assessment of the risk of the recipient related to the condition imposed on the average strength of standard C20/25 concrete was made. Histogram of the compressive strength distribution of concrete (Fig. 2):

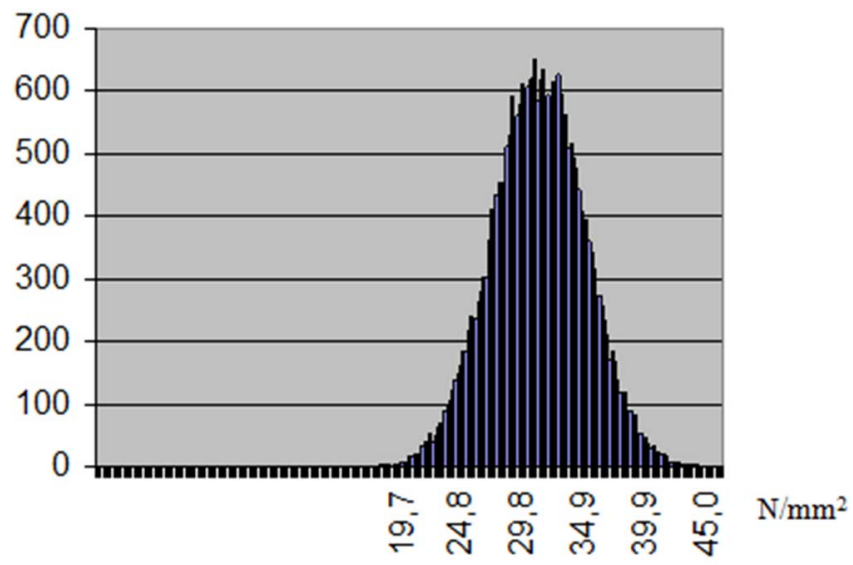

Fig. 2. Histogram of C20/25 concrete class produced in 1994-2000.

Checking the quality of compressive concrete strength is connected with committing two types of errors. The probability of making the mistake of the first type cannot be arbitrarily small. The probability of rejecting the hypothesis in the case when it is true can be made small only at the expense of increasing the probability of the second type of error, i.e. assuming a hypothesis when it is false. The recipient is interested in whether the real mean value of the compressive strength of concrete was low, say $29 \mathrm{~N} / \mathrm{mm}^{2}$, or was high, e.g. $36 \mathrm{~N} / \mathrm{mm}^{2}$. In each of these situations it is possible that the average will be in the area of the rule, i.e. between (1):

$$
P\left[33-c \leq X \leq 33+c / H_{o}\right]=1-\alpha=95 \%
$$

If this is the case, the operational rule proposed as a result of testing the hypotheses will be incorrectly suggesting that the engineer acts as if the real mean value was $33 \mathrm{~N} / \mathrm{mm}^{2}$. The probability of this possibility is marked by $\beta$. You can set them for each specific real value of the mean value. For example, if the real mean value is $29 \mathrm{~N} / \mathrm{mm}^{2}$, then this 
operational rule (for $\alpha=5 \%$ ) the probability of mistakenly accepting the hypothesis that the average is $33 \mathrm{~N} / \mathrm{mm}^{2}$, is equal to (2):

$$
\beta=P[28,68 \leq X \leq 37,32 / m=33]
$$

If the real mean value is $29 \mathrm{~N} / \mathrm{mm}^{2}$, the engineer using this method will more often assume that the real mean value is $33 \mathrm{~N} / \mathrm{mm}^{2}$. If the real mean value is $25 \mathrm{~N} / \mathrm{mm}^{2}$, the probability of the second type of error will decrease to about $15 \%$, if the real value is 38 , the probability $\beta$ is only $39 \%$. This can be graphically represented using the operatingcharacteristic curve of the rule (Fig. 3).

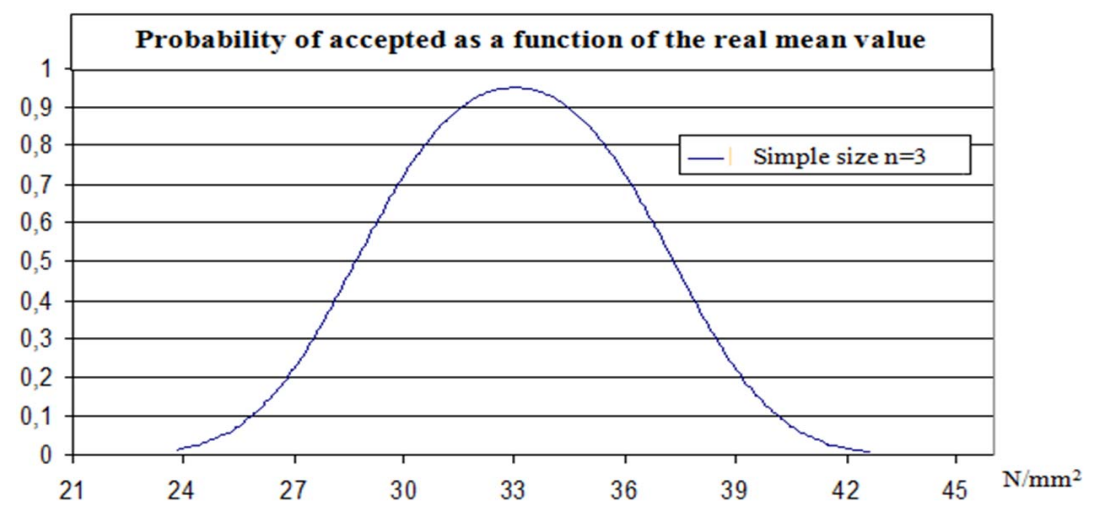

Fig. 3. OC curve of the operational rule for testing the mean value of compressive strength, $\alpha=0.05$, for sample size $n=3$.

If the mean value of compressive strength is $33 \mathrm{~N} / \mathrm{mm}^{2}$, then $\beta$ is equal to $1-\alpha=95 \%$. Because the high probabilities of the second type of errors should not be tolerated, the engineer should try to reduce them. This can be achieved by reducing the length of the acceptance interval of hypothesis $2 \mathrm{c}$, or by increasing the value of $\alpha$ - the probability of error of the first type, or increasing the sample size from three to a sufficiently large number. For the same significance level (e.g., $\alpha=5 \%$ ), the increasing sample size will decrease $\sigma$, and thus the width of the $2 \mathrm{c}$ range will also decrease.

By constructing the operation-characteristic curve for $n=6$, we get a set of values $\beta$ which is always smaller than the corresponding values of $\beta$ for the sample with the number $\mathrm{n}=3$. For example, with the sample size $\mathrm{n}=6$ and $\alpha=5 \%, \mathrm{c}=3.06$ and the curve OC of probabilities $\beta$ has the following form - Fig. 4 .

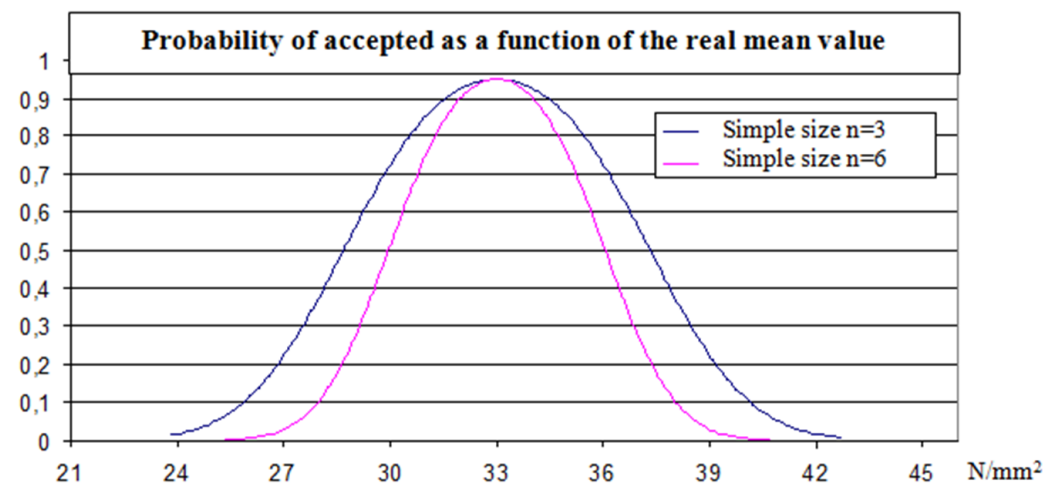

Fig. 4. OC curve of the operational rule for testing the mean value of compressive strength, $\alpha=0.05$, for sample size $\mathrm{n}=3$ and $\mathrm{n}=6$. 
An engineer, guided by the reliability of the results analysis method and at the pre-set $\alpha$, can determine the necessary sample size. In order to preserve $\alpha$ at $5 \%$, as well as to reduce $\beta$ to at most $20 \%$, assuming that the real average is $33 \mathrm{~N} / \mathrm{mm}^{2}$, it is easy to calculate that the sample size must be at least 10 . If this number of trials entails excessive costs, the consequences of sampling should be balanced by comparing the first and second types of errors in an economic context.

Table 3. Probability of making a $\beta$ error for the mean value of compressive strength of $29 \mathrm{~N} / \mathrm{mm}^{2}$ and different sample size.

\begin{tabular}{|c|c|}
\hline Sample size & Producer risk - $\boldsymbol{\beta}$ (Type - I I Error) \\
\hline $\mathrm{n}=3$ & 0.55 \\
\hline $\mathrm{n}=6$ & 0.29 \\
\hline
\end{tabular}

The OC curves of the operating rule for testing the actual average strength of $\mathrm{m}=33 \mathrm{~N} / \mathrm{mm}^{2}$, at $\alpha=0.05$ and different sample sizes are characterized by the different probabilities of accepting a real average strength of $29 \mathrm{~N} / \mathrm{mm}^{2}$. The values of the obtained OC curves protect the recipient to a different degree before accepting a party with a real average of $29 \mathrm{~N} / \mathrm{mm}^{2}$. The analysis shows that the real average compressive strength of class C20/25 concrete produced by one of the ready-mix concrete plants is $29 \mathrm{~N} / \mathrm{mm}^{2}$, so when collecting samples of $n=3$, the probability of error of the second type of such a batch will be 0.55 , and at the number $\mathrm{n}=6$ will be 0.29 (table 3 ).

\section{Summary}

The OC curve is a widely accepted tool to quantify the producer's risk as well as the consumer's risk. Sampling plans with large sample sizes are better able to discriminate between acceptable and unacceptable quality. Therefore, fewer lots of unacceptable quality are accepted and fewer lots of acceptable quality are rejected.

Verification of the compliance criterion for compressive strength using the operatingcharacteristic curves of the operational rule for testing the average strength leads to the following conclusions:

- The operating-characteristic curve of the operational rule for testing the average compressive strength of concrete allows the direct reading of the value of the second type error, and thus directly defines the risk of the recipient when the real average differs significantly from the assumed (designed) strength;

- For a given $n$ element test, reducing the probability $\alpha$ of committing a first type error (test significance level) increases the probability of $\beta$ to commit a second type error;

- The reduction of $\beta$ error with the same $\alpha=0.05$ can be obtained by increasing the sample size;

- Determining the sample size, as well as errors of the first and second type, should be an expression of a compromise between quality and economy;

- Thus a good compliance scheme should ensure that the producer's risk and the consumer's risk are at an acceptable level and are properly distributed between the producer and the consumer. Here lies the importance of OC curves, which can be used to evaluate the desired compliance scheme. 


\section{References}

1. O. Hryniewicz, (Nowoczesne metody statystycznego sterowania jakościa, PAN, 2000)

2. J. Steczkowski, A. Zielas, (Metody statystyczne w badaniu zjawisk jakościowych, PWE, 1997)

3. J. Murzewski, (Bezpieczeństwo konstrukcji budowlanych, Arkady, 1970)

4. A. Sowa, (Problemy jakości budownictwa, Wrocław-Kudowa Zdrój, 1981)

5. L. Taerwe, Mater Struct, 21, 13-20 (1988)

6. Sz. Woliński, K. Wrobel, (Niezawodność konstrukcji budowlanych, OPRz, 2002)

7. R. Caspeele, M. Sykora, L. Taerwe, Mater Struct, 47(1-2), 105-116 (2014)

8. R. Rackwitz, Mater Struct, 16, 259-267 (1983)

9. J.M. Juran, F.M. Gryna, R.S. Bingham, (Quality control handbook, McGraw Hill, New York, 1979)

10. R. Caspeele, L. Taerwe, Mater Struct 44(7), 1219-1231 (2011)

11. L. Taerwe, R. Caspeele, in: D. Proske, M. Mehdianpour, L. Gucma (eds) (Proceedings of 4th international probabilistic symposium. Berlin, 57-70, 2006)

12. M. Holický, M. Sýkora, in: M. H. Faber, J. Köhler, K. Nishijima, (Proceedings of ICASP11, 11th International Conference on Applications of Statistics and Probability in Civil Engineering, ETH Zurich, Switzerland, 969-976, 2011)

13. EN 206, Beton. Wymagania, właściwości, produkcja i zgodność

14. Skrzypczak I., Buda-Ozog L., Kokoszka W., Slowik M., JCEEA 32(62-3/I/15), 403412, (2015), http://doi.prz.edu.pl/pl/pdf/biis/295

15. Skrzypczak I., Wolinski Sz., AIL, 53(3), 479-495 (2007)

16. Szczygielska E., Tur V., Budownictwo i Architektura, 12(3), 223-230 (2013)

17. Beal A.N., The Structural Engineer, 87(10), 12-13 (2009)

18. Toplis, P., The Structural Engineer, 86(23/24) 43 (2008)

19. Pawlikowski J., (Systemy zapewnienia jakości w budownictwie, ITB 2003)

20. Mirza S. A., MacGregor J. G., Journal of the Structural Division, 105(6), 1021-1037 (1979)

21. Skrzypczak I., Zeszyty Naukowe Politechniki Rzeszowskiej. Budownictwo i Inżynieria Środowiska, 58(2), 371-383 (2011) 